\title{
A Journey to the East: Child Psychiatry in Asia
}

\author{
Daniel Fung and Nikki Lim-Ashworth \\ Department of Developmental Psychiatry, Institute of Mental Health, Singapore
}

The development of child mental health services in Asia is a recent one [1] and, with some exceptions, is largely based on Western models of care. Organic support for children and their emotional needs originated through families and communities rather than in formal medical settings. With globalization and the increasing recognition of young people's distress through mainstream and social media, the practice of child psychiatry is likely to receive more attention in medical schools and more doctors are likely to be trained. Most countries have recognized the classification systems of the World Health Organisation and the American Psychiatric Association in defining the medical construct of mental health disorders, and incorporating them into health, education, and social systems of care. This formalization of mental health services, even in low income countries, has meant that almost every country in Asia has psychiatrists, and some of them will work with young patients, although most do not do so exclusively. However, the numbers are still small, and sub-specialization in child psychiatry continues to be an issue. In Asia, the number of child psychiatrists for every 100000 children aged 14 years or younger ranges between 1.97 and 3.95 in more developed states and between 0.01 and 0.09 in developing ones [2]. By comparison, Switzerland and Norway have the highest such numbers at 48.30 and 47.74 , respectively. At present, Asia has 1.4 billion or approximately $56 \%$ of the global young population under the age of 19 [3] - as countries develop and mature, mental health care for the young will become more apparent and critical.

The Asian Society of Child and Adolescent Psychiatry and Allied Professions (ASCAPAP) was formed in 1996, shortly after the International Association of Child and Adolescent Psychiatry and Allied Professions (IACAPAP) World Congress met in Kyoto, Japan, in 1990. It was propelled by the need to develop a regional, culturally-sensitive understanding and sharing of expertise in this relatively new area of work. Asia is progressively seen as both an economic powerhouse as well as a potential leader in developing value-based care for its large populations, a concept that is increasingly becoming relevant

This is an Open Access article distributed under the terms of the Creative Commons Attribution Non-Commercial License (https://creativecommons.org/licenses/by-nc/4.0) which permits unrestricted non-commercial use, distribution, and reproduction in any medium, provided the original work is properly cited. to the developed world, where healthcare costs have burgeoned and become out of control. For instance, a cost-effective and resource-efficient child and adolescent mental health care model has been developed in Singapore. It leverages on systematic assessment and early detection in close collaboration with community-based partners (e.g., schools, primary care physicians), and implements broad-spectrum interventions that are transdiagnostic in nature [4]. The need to deploy a limited number of child psychiatrists to address the scale of work in Asia can result in innovations in service developments and new cost effective models of care that look to countries that can and are willing to take the lead [5]

Korea is one of the forerunners in the advancement of child psychiatry in Asia for a number of reasons: it is one of the founding members of ASCAPAP and hosted the second ASCAPAP Congress in 1999 as well as the 1st attention-deficit/hyperactivity disorder Asian Congress, 2012, in Seoul. In addition, Korea's academics and clinicians have been making significant contributions to the science of child psychiatry. The Journal of the Korean Academy of Child and Adolescent Psychiatry (JKACAP) is one of the three Asian-based journals, the others being the Japanese Journal of Child and Adolescent Psychiatry and the Journal of Indian Association for Child and Adolescent Mental Health, dedicated to the field of child and adolescent psychiatry. The JKACAP is one of the leading examples for Asia, and is celebrating its 30th anniversary this year.

Asia will again be the highlight of the IACAPAP World Congress as it hosts its 24th World Congress in Singapore in 2020. This will be an opportunity to showcase the breadth and knowledge of child psychiatry in the region and look at new ways to develop services by moving upstream and considering the developmental perspective in preventing and mitigating problems before they appear.

\section{REFERENCES}

1) Rey JM, Assumpção FB, Bernad CA, Çuhadaroğlu FC, Evans B, Fung D, et al. History of child and adolescent psychiatry. In: Rey JM, editor. IACAPAP e-Textbook of child and adolescent mental health. Geneva: International Association for Child and Adolescent Psychiatry and Allied Professions;2015.

2) Sourander A, Chudal R, Skokauskas N, Al-Ansari AM, Klomek AB, Pornnoppadol C, et al. Unmet needs of child and adolescent psychiatrists among Asian and European countries: does the Human 
Development Index (HDI) count? Eur Child Adolesc Psychiatry 2018;27:5-8.

3) United Nations. 2019 Revision of world population prospects. [cited 2019 Aug 21]. Available from URL: https://population. un.org/wpp/Graphs/Probabilistic/POP/0-19/935.

4) Fung DS, Lim-Ashworth NS. Child psychiatry without psychia- trists: a new model for old problems. Ann Acad Med Singapore 2017:46:42-43.

5) Juengsiragulwit $\mathbf{D}$. Opportunities and obstacles in child and adolescent mental health services in low- and middle-income countries: a review of the literature. WHO South East Asia J Public Health 2015;4:110-122. 